\title{
A systematic review of 3D scanners and computer assisted analyzes of bite marks: searching for improved analysis methods during the Covid-19 pandemic
}

\author{
Piret Vilborn ${ }^{1}\left[\right.$ ] Herman Bernitz ${ }^{1} \mathbb{D}$
}

Received: 16 April 2021 / Accepted: 7 July 2021 / Published online: 24 July 2021

(c) The Author(s), under exclusive licence to Springer-Verlag GmbH Germany, part of Springer Nature 2021

\begin{abstract}
The global Covid-19 pandemic has forced forensic dentists to improve infection control methods. This search investigated the practical utilization of different 3D scanners to record and to analyze bite marks in the skin- and inanimate objects with this aim in mind. A systematic review of the literature using keywords like "human bite mark", "bite mark analyzes", "3D analyzes", "3D scanning", "forensic odontology", and "forensic dentistry" was performed in three scientific databases: MEDLINEOvid $®$, Pubmed ${ }^{\circledR}$ and Google Scholar. The initial search yielded 263 full-text articles, of which 15 were considered eligible and current within the last 10 years. 3D scanners and computer-assisted human bite mark analyzes showed potential advantages and can be effectively used in forensic odontology on skin and inanimate objects. These technologies minimize the number of people being exposed to pathogens, simplify the chain of evidence, facilitate immediate information exchange between the team members and enable the virtual presentation of the expert witnesses in a court of law.
\end{abstract}

Keywords Forensic science $\cdot$ Forensic odontology $\cdot$ Covid-19 $\cdot$ 3D documentation $\cdot$ Photogrammetry $\cdot 3 \mathrm{D}$ computerassisted analyzes $\cdot$ Bite marks

\section{Introduction}

Covid-19 has presented new challenges in every sphere of life including the science of bite mark analysis. The pandemic has seen an increase in the number of domestic violence cases, murders, cases involving sexual assault, child abuse, and the neglect of the elderly [1-4]. Human bite marks were observed in many of these cases [5].

Currently collecting evidence for bite marks poses a risk of occupational exposure to Covid-19 infection for the forensic dentist in a mortuary setting, particularly if the necessary precautionary measures are lacking $[6,7]$. The use of alternative methods, such as threedimensional (3D) scanning technology which are less invasive, digitally transferrable, and equally accurate to

Piret Vilborn

vilborn@gmail.com

1 Department of Oral Pathology and Oral Biology, School of Dentistry, Faculty of Health Sciences, University of Pretoria, PO Box 1266, Pretoria 0001, South Africa conventional methods should now be considered. Since the onset of Covid-19, the Pretoria team of forensic odontologists have included 3D scanning of both, the bite marks and the suspect's dentition in their analysis of the relevant cases. Bitemarks will always undergo a degree of warpage, shrinkage, and distortion with time [8-10]. A 3D scan is thus, a representation of a distorted bite mark [11] in either skin or an inanimate object. A 3D scan is a snapshot in time that will capture and freeze the images that we know are already distorted. A 3D scanner generates point clouds from geometric data gathered from the surface of an object. The object's shape is reconstructed from the digital data on the known spatial position of each measurement point. Different scanning and processing software programs are used to generate comparison of dental casts and scanned dentition [12].

This systematic review aims to investigate the practical utilization of different 3D scanners in recording bite marks in skin- and inanimate objects and the use of computerassisted methods in human bite mark analyzes during and after the Covid-19 pandemic. 


\section{Methods}

In August 2020, during the height of the South African pandemic, a systematic review of the literature was performed using an online search in three scientific databases: MEDLINEOvid®, Pubmed $®$, and Google Scholar. As a result of rapid development of technology, only articles from 2011 onwards were considered relevant. Key words such as "human bite mark,", "bite mark analyzes", "3D analyzes", "3D scanning", "forensic odontology", and "forensic dentistry" were searched. The search was expanded by checking the reference lists of the articles. Additional mining of above mentioned databases was conducted in February 2021 for the purpose of this review. The articles obtained by the search were screened and selected by two operators. Only English language full-text articles with indexed abstracts published in ISI-accredited dental, forensic, and legal medicine journals were included. Short communications, letters to the editor, case reports, ordinary, and systematic reviews were excluded from the results.

From the articles that fulfilled the criteria, the following data were extracted: (1) the aim of the study, (2) the sample size, (3) the bite mark substrate (4) registration techniques and the scanners used, (5) software, and (6) the study outcome.

\section{Results}

The initial search yielded 263 full-text articles, of which 248 did not meet the selection criteria. A PRISMA[13] flowchart is presented in a Fig. 1.

The year of publication, authors, titles, and journals are presented in the Table 1.

Fifteen eligible articles were divided on a basis of the analysis target as follows:

A Studies assessing the reliability of measurements of different 3D scanners are presented in the Table 2 (6 articles)

B Studies utilizing 3D comparison of the dental crown morphology of the anterior dentition are presented in the Table 3 ( 3 articles)

C Studies on suitability of different computer-assisted methods for bitemark analyzes are presented in the Table 4 (6 articles)

\section{Discussion}

From the search it became clear that 3D digital scanning of bite marks enables accurate and fast recording of the bite marks in soft substances such as cheese, chocolate, pears, apples, and human skin without further distortion of the evidence during impression taking $[10,11]$. While using digital

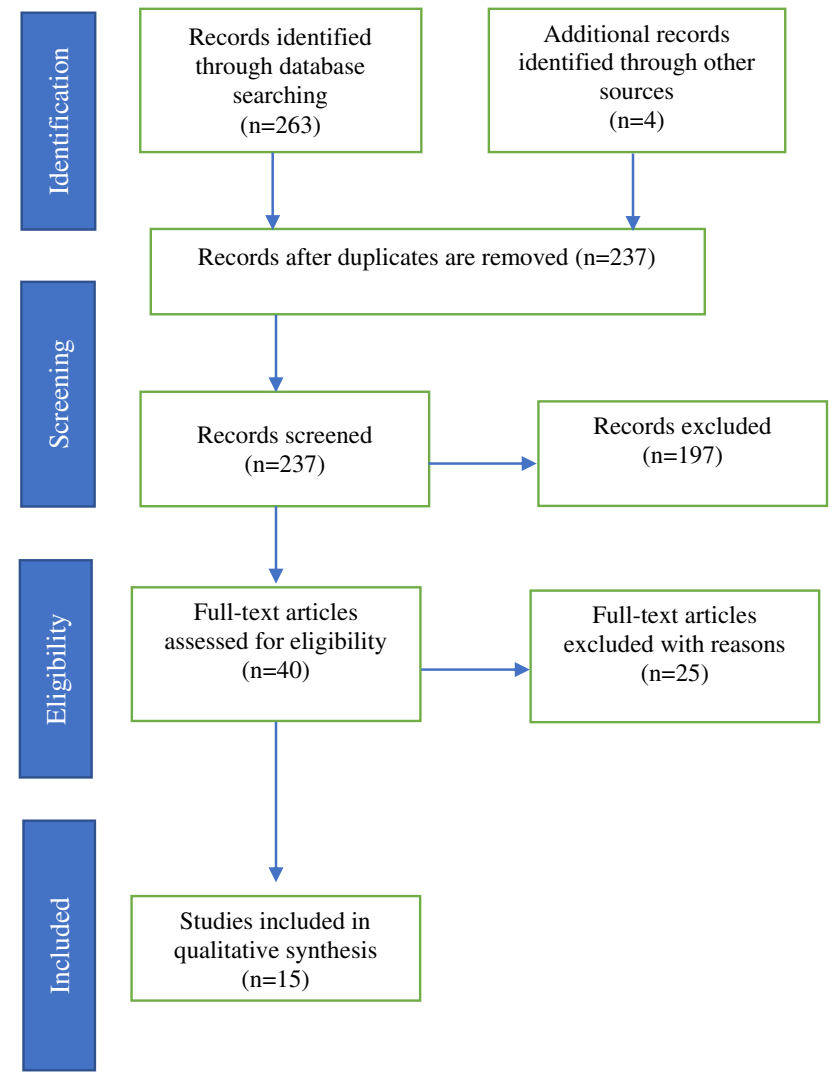

Fig. 1 Flow diagram of the search and selection process [13].

scanners, an exposure to pathogens can be minimized and several steps can be eliminated. These include mixing an impression material, waiting for setting of impressions and casting of models from impressions [27]. Taking impressions of the suspect's dentition can sometimes be problematic due to noncompliance and gagging which can be alleviated by the small heads available in some of the scanners [28, 29]. Maintaining a chain of evidence becomes far simpler and can be digitally traced. A digital file can be uploaded to a cloud server for immediate communication with the forensic team members [30]. It minimizes the number of people being exposed to the evidence or suspect from a pandemic control point of view and allows the team to work remotely via cloud server. It also enables for the virtual presentation of the expert witness in a court of law [31].

\section{Studies assessing the reliability of different 3D scanners}

The study on contact 3D scanners showed that the contact between the scanner and the bitemark was problematic as the evidence could inadvertently be damaged. Contact scanners were also unable to capture surfaces with marked concavity 
Table 1 Studies included in this systematic review

\begin{tabular}{|c|c|c|c|}
\hline Year & Author & Title & Journal \\
\hline 2012 & Naether et al.[10] & $\begin{array}{l}\text { The examination and identification of bite marks } \\
\text { in foods } \\
\text { using 3D scanning and 3D comparison methods }\end{array}$ & Int J Legal Med (2012) 126:89-95 \\
\hline 2014 & Martin-de-las-Heras et al. [14] & $\begin{array}{l}\text { A quantitative method for comparing human denti- } \\
\text { tion with tooth marks using three-dimensional } \\
\text { technology and geometric morphometric } \\
\text { analysis }\end{array}$ & $\begin{array}{l}\text { Acta Odontologica Scandinavica. 2014; } 72 \text { : } \\
\text { 331-336 }\end{array}$ \\
\hline 2015 & Molina et al.[12] & Accuracy of 3D Scanners in Tooth Mark Analyzes & J Forensic Sci. (2015), 60, S1 S222-226 \\
\hline 2015 & Przystańska et al.[15] & $\begin{array}{l}\text { The Effectiveness of 2D and 3D Methods in the } \\
\text { Analysis of Experimental Bite Marks }\end{array}$ & Dent. Med. Probl. 52, 1 (2015), 86-92 \\
\hline 2016 & de Sainte Croix et al.[16] & $\begin{array}{l}\text { Three-dimensional imaging of human cutaneous } \\
\text { forearm bite marks in human volunteers over a } \\
4 \text { day period }\end{array}$ & $\begin{array}{l}\text { Journal of Forensic and Legal Medicine } 40 \text { (2016) } \\
\text { 34-39 }\end{array}$ \\
\hline 2017 & Chong et al.[17] & $\begin{array}{l}\text { A Pilot Study to Analyze the Uniqueness of } \\
\text { Anterior Teeth Using a Novel Three-dimensional } \\
\text { Approach }\end{array}$ & $\begin{array}{l}\text { Journal of Forensic Identification. 2017; 67(3):361- } \\
\quad 78\end{array}$ \\
\hline 2017 & Franco et al. [18] & $\begin{array}{l}\text { Uniqueness of the anterior dentition three-dimen- } \\
\text { sionally assessed for forensic bitemark analysis }\end{array}$ & $\begin{array}{l}\text { Journal of Forensic and Legal Medicine } 46 \text { (2017) } \\
58-65\end{array}$ \\
\hline 2017 & Franco et al.[19] & $\begin{array}{l}\text { Three-dimensional analysis of the uniqueness of } \\
\text { the anterior dentition in orthodontically treated } \\
\text { patients and twins }\end{array}$ & Forensic Science International 273 (2017) 80-87 \\
\hline 2017 & Rajshekar et al.[20] & $\begin{array}{l}\text { The reliability and validity of measurements of } \\
\text { human dental casts made by an intra-oral 3D } \\
\text { scanner, with conventional hand-held digital } \\
\text { calipers as the comparison measure }\end{array}$ & Forensic Science International 278 (2017) 198-204 \\
\hline 2018 & Ali et al. [21] & $\begin{array}{l}\text { Analysis of Intercanine Distance and Dimensional } \\
\text { Changes in Bite Marks on Foodstuffs Using } \\
\text { Cone Beam Computed Tomography }\end{array}$ & $\begin{array}{l}\text { The American Journal of Forensic Medicine and } \\
\text { Pathology 1(2018) }\end{array}$ \\
\hline 2018 & Corte-Real et al. [22] & $\begin{array}{l}\text { Tri-dimensional pattern analysis of foodstuff bite } \\
\text { marks - A pilot study of tomographic database }\end{array}$ & Forensic Science International 288 (2018) 304-309 \\
\hline 2019 & Fournier et al. [23] & $\begin{array}{l}\text { Three-dimensional analysis of bite marks using an } \\
\text { intraoral scanner }\end{array}$ & Forensic Science International 301 (2019) 1-5 \\
\hline 2019 & Ramos et al. [24] & $\begin{array}{l}\text { A new method to geometrically represent bite } \\
\text { marks in human skin for comparison with the } \\
\text { suspected dentition }\end{array}$ & $\begin{array}{l}\text { Australian Journal of Forensic Sciences } 51 \text { (2019) } \\
\text { Issue } 2\end{array}$ \\
\hline 2020 & Fournier et al. [25] & $\begin{array}{l}\text { Three-dimensional analysis of bite marks: A vali- } \\
\text { dation study using an intraoral scanner }\end{array}$ & Forensic Science International 309 (2020) 110,198 \\
\hline 2020 & Molina et al.[26] & $\begin{array}{l}\text { Dental parameter quantification with semiautoma- } \\
\text { tized computational technology for the analysis } \\
\text { of human bite marks }\end{array}$ & Australian Journal of Forensic Sciences (2020) 1-11 \\
\hline
\end{tabular}

[12]. This has led to increased interest in noncontact methods such as laser scanning. The 3D laser scanners have proved their precision for different applications. However, the difficulty detecting sharp edges, especially incisal edge of the anterior incisors may provide false presentation of the tooth morphology. While using the 3D laser scanners for dental casts and biting edges in practical forensic cases, the margin of the error should be considered [12].

Utilization of fringe pattern protection scanners, also known as optical surface scanners such as Gom ATOS III (Gom, Braunschweig, Germany) in 3D documentation of bite marks was reported in two articles $[10,15]$. The method is noninvasive, displays high resolution results, and does not damage the evidence [10]. The difficulties of capturing tiny areas and deep structures of the surface and the cost of equipment have been reported in the literature [10, 32].

The evidence suggests that intra- and inter- arch measurements obtained from digital dental models using intraoral scanners is equivalent to dental plaster models or digital images generated from conventional dental impressions [33]. Zfx InraScan intraoral 3D scanner and it's virtual measuring tool was found valid for measuring key features in dental casts [20]. The studies done by Fournier et. al. [23, 25] proposed a protocol for the bite-mark analyzes using Planmeca Emerald $®$ intraoral scanner. In a validation study it was found reliable on wax, cheese, and chocolate, but yielded 


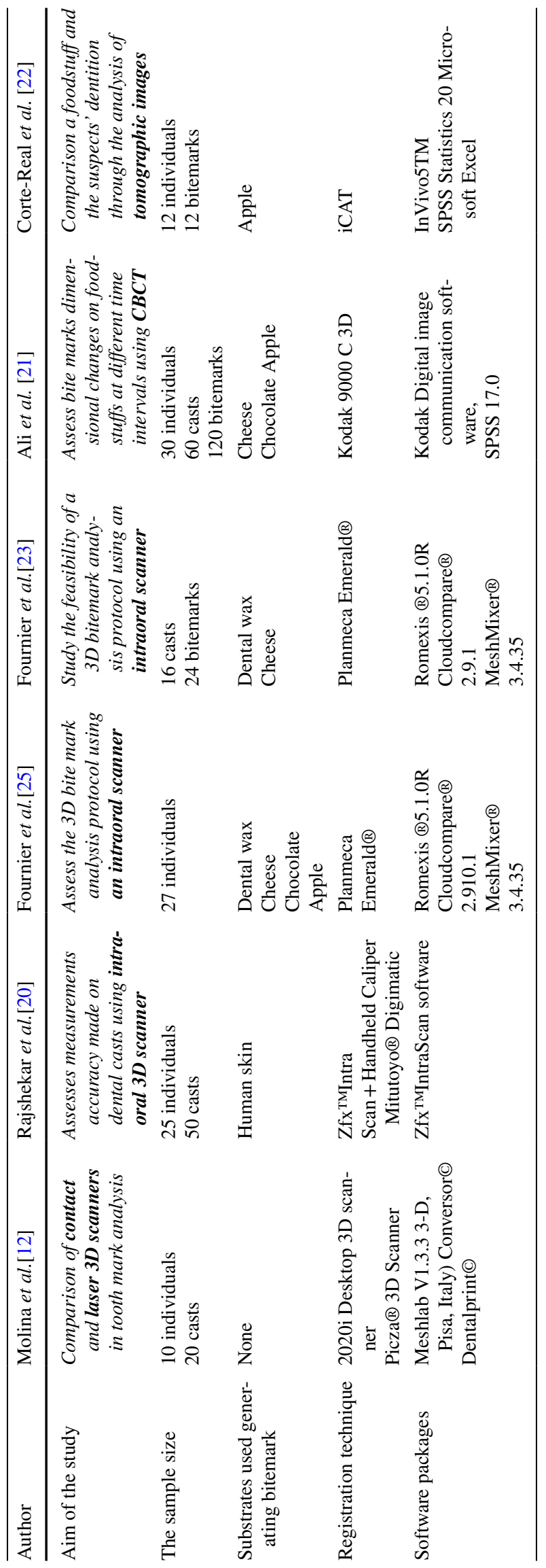


Table 3 Overview of studies utilizing 3D comparison of the dental crown morphology of the anterior dentition

\begin{tabular}{|c|c|c|c|}
\hline Author & Chong et al.[17] & Franco et al. [18] & Franco et al.[19] \\
\hline Aim of the study & $\begin{array}{l}\text { Use intraoral 3D scanner and } 3 D \\
\text { analyzes software to investigate } \\
\text { the uniqueness of the anterior } \\
\text { human dentition (UHD) among } \\
\text { patients who had completed } \\
\text { orthodontic treatment. Deter- } \\
\text { mine the feasibility of a com- } \\
\text { bined intraoral 3D scanner and } \\
\text { 3D analyzes software approach } \\
\text { to bite mark analyze }\end{array}$ & $\begin{array}{l}\text { Assess the UHD in the anterior } \\
\text { dentition based on systemati- } \\
\text { cally reducing the } 3 D \text { quantity } \\
\text { of dental material analyze and } \\
\text { using slices of the analyzed } \\
\text { dental material }\end{array}$ & $\begin{array}{l}\text { Prove the UHD } 3 D \text { comparing the } \\
\text { dental crown morphology of the } \\
\text { anterior dentition in of orthodon- } \\
\text { tically treated patients, twins, and } \\
\text { orthodontically treated twins in } \\
\text { relation to a threshold sample of } \\
\text { identical dentitions }\end{array}$ \\
\hline The sample size: Individuals & $\begin{array}{l}20 \text { individuals } \\
44 \text { casts }\end{array}$ & 445 casts & 445 casts \\
\hline $\begin{array}{l}\text { Substrates used generating } \\
\text { bitemark }\end{array}$ & none & none & none \\
\hline Registration technique & $\begin{array}{l}\text { 3MLava Chairside Oral Scanner } \\
\text { C.O.S. (3 M ESPE St. Paul, } \\
\text { MN) }\end{array}$ & $\begin{array}{l}\text { XCAD 3D® } \\
\text { (XCADCAM Technology®, Sao } \\
\quad \text { Paulo, SP, Brazil) }\end{array}$ & $\begin{array}{l}\text { XCAD 3D® } \\
\text { (XCADCAM Technology®, Sao } \\
\text { Paulo, SP, Brazil) }\end{array}$ \\
\hline Software packages & $\begin{array}{l}\text { Meshlab V1.3.2, Pisa, Italy) } \\
\text { Geomagic Control (Morrisville, } \\
\text { NC) }\end{array}$ & $\begin{array}{l}\text { Geomagic Studio® (3D Sys- } \\
\text { tems®, Rock Hill, SC, } \\
\text { USA) software package (GS), S.® } \\
8.0 \text { (Tibco }{ }^{\circ} \text { Palo } \\
\text { Alto, California, USA) }\end{array}$ & $\begin{array}{l}\text { Geomagic Studio }{ }^{\circledR}(3 D \text { Systems } ® \text {, } \\
\text { Rock Hill, SC, } \\
\text { USA) software package (GS), S. }{ }^{\circ} \\
8.0 \text { (Tibco }{ }^{\circledR}, \text { Palo } \\
\text { Alto, California, USA) }\end{array}$ \\
\hline
\end{tabular}

the poorest results in apples. The use of any type of scanner and associated equipment always requires a high degree of training and expertise. These devices showed an excellent potential for use in bite-mark analysis.

The CBCT-assisted analysis of bite marks was considered a nondestructive, accurate, and simple. Ali et al. [21] concluded that CBCT images of bite marks displayed no distortion artifacts and enabled accurate 3D measurements. Corte-Real et. al. [22] showed in their study that bite mark analysis could be done through software that searches for matching dentitions in a CBCT database. This could add value in the identification process of potential suspects where countries have one or more national databases for all the performed radiographic images. Using ionizing radiation may pose potential risk to the operator and the suspect [34]. This obviously does not apply to the bitemarks on the bodies observed and investigated in the mortuary. The availability of the CBCT machines and the cost of the procedure might be an obstacle for utilizing this novel approach in less developed countries. In spite of these shortcomings, CBCT could provide a potential alternative modality for recording the bite marks in forensic odontology, especially on foodstuffs [35].

Photogrammetry in 3D documentation of skin bite marks was published for the first time in 2003 by Thali et al. [36]. A series of overlapping photos from different points of view around a targeted object are taken and the 2D photographs are combined into a true-to-scale 3D model of the object. Simplicity, inexpensiveness, free software, and somewhat trivial technical requirements of photogrammetry enable us to create a textured 3D surface model [37]. The accuracy of this technique has been proven to be comparable to the laser scanners [38]. Photogrammetry has been routinely utilized in forensic 3D documentation of skin injuries [39-41]. The use of photogrammetry was demonstrated by De Sainte Croix et al. [16] in our systematic review.

\section{Studies utilizing 3D comparison of the dental crown morphology of the anterior dentition.}

The uniqueness of human dentition (UHD) could be assessed using 2D (flatbed scanning and photography) and 3D (laser scanning and intraoral scanning) image registration [42]. Chong et al. [17] used intraoral 3D scanner and 3D analyzes software to investigate the UHD in the orthodontically treated study population on human anterior dentition. The authors found that anterior dentition was unique within their study population as no perfect matches were detected. They concluded that using 3D scanner and commercially available 3D analyzes software were highly encouraging methods in bite-mark analyzes particularly in the absence of any positive DNA assay [17]. In two studies by Franco et al. [18, 19] they investigated the uniqueness of the human dentition utilizing 3D methods in randomly selected subjects. The subjects included orthodontically treated patients and twins to increase the reliability of the study [18]. The first study analyzing incisal edges did not show uniqueness, but when 


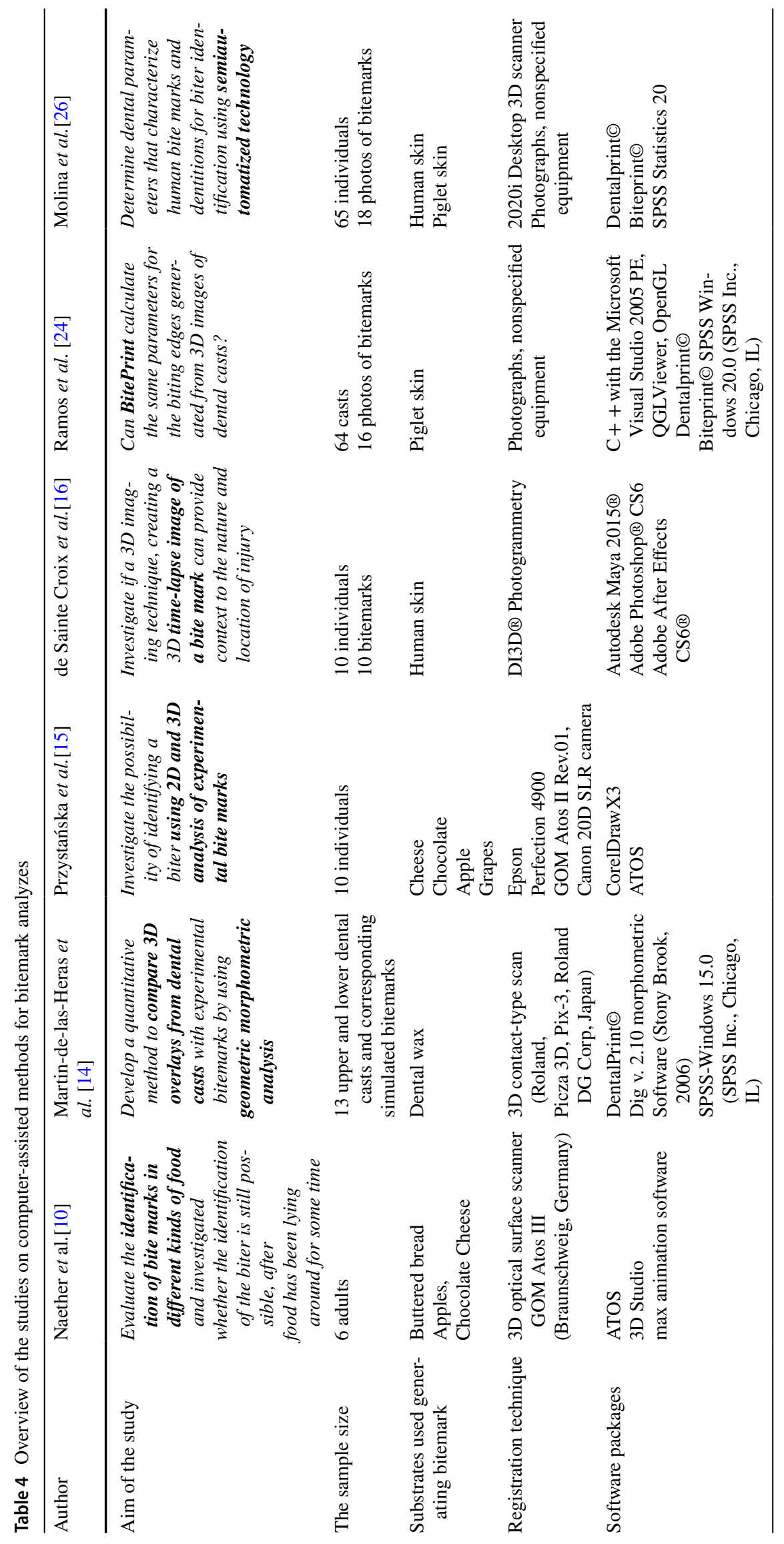


the complete crowns of the anterior teeth were included, UHD was demonstrated [18, 19].

It must be understood that the presence of recognizable dental features, nicks, chips, and imperfections are required to correctly match suspects to bitemarks. A lack of features seen in orthodontically treated patients, especially in skin bite cases will create problems in identifying a perpetrator and be impossible to present in the court of law [9].

After considering the research results 3D scanners and computer-assisted methods in bite mark analyszes showed promising results. Small sample size, lacking statistical methods for data comparison, missing intra- and inter-examiner calibrations, nonvalidated software for 3D shape comparison or relatively scarcity of studies performed in vitro present the main limitations in studies included.

\section{Studies on computer-assisted methods for bitemark analyzes}

Computer-assisted methods for bitemark analyzes enable experts to work remotely and seek advice from the other team members and colleagues during pandemic. It must be noted, that computers cannot manufacture that which does not exist. Digital analyzes of the bite mark can only enhance existing features and enable the proficient presentation of these features. The use of 3D imaging technology offers practical advantages to the courtroom, specifically with respect to the juror's understanding of technical language [31].

Biting is a dynamic process. Thus, bite mark analysis is based on a combination of morphological and positional data [43]. Computer assisted graphics and animations have showed the potential for accurate representation of bite marks in all three dimensions, compare the dentitions of presumed biter to the evidence and match the corresponding biter to the bite-mark among several suspects [44]. ATOS software enables an automatic computation of the deviation between the two meshes, thus, allows an easy and very accurate analysis and interpretation of the results. 3D Studio Max software allows dynamic comparison during the animated act of biting, where 3D match or nonmatch is clearly detectable [10].

De Sainte Croix et al. [16] successfully created 3D timelapse animations, which can be viewed on most electronic devices. The quality of DI3D Photogrammetry system was accurate enough to enable the animations to illustrate the color and shape of bruising. Some distortions were present around the edges of 3D model. The animations can have significant benefit to the photographic evidence presentation in court setting, especially if the presentation has been made virtually [16].
Realistic 3D perspective allows the placement of a higher number of landmarks [44, 45]. Additionally, automated image superimposition and mesh processing leads to improved digital 3D image analyzes and interpretation of bitemarks [18]. 3D capture of the bitemark and digital analysis provide images that have less angular and perspective distortion, which results in less measurement errors [24]. It can be performed using high-tech commercially available as well as special forensic odontology software such as Dentalprint $\odot$, BluePrint $\odot$, and Biteprint $\odot$ $[12,24,26]$.

Semiautomated BluePrint $($ software enables the investigator to compare the photographs of a bite mark with the biting edges of a dental cast. It generates data on the dental parameters required for identification (e.g. intercanine distance, rotation, eccentricity, angular position, and distance to the arch of each tooth mark). BitePrint $\odot$ represents the biting edges of dental casts as a set of geometric coefficients, offering a measurable, semiautomatic, and less subjective analysis. Molina et al. [26] evaluated the accuracy and reproducibility of dental parameters between photographs of bite marks and dental casts using semiautomated technology. The sensitivity of this technology was found to be $92 \%$ and specificity 53\%. The accuracy of these programs can be applied in practical forensic dentistry and in criminal trials involving human bite mark cases [24, 26].

\section{Conclusion}

The global pandemic has forced us to search for new and innovative techniques which are safer to use in our day to day practice of forensic science. Three-dimensional scanners have shown potential advantages and can be used in forensic odontology on the skin and inanimate objects. The analyzes of the bite marks depends on quality, quantity, and the presence of recognizable features in a pattern associated analysis. The latter requires only a degree of accuracy which is standard in the majority of 3D scanners. Training and expertise on 3D scanners and computerized technologies is an absolute prerequisite for forensic dentists to obtain accurate results. The authors believe that in changing world the 3D scanning and analyzing techniques will replace the methods which were derived in a world free of Covid-19, Ebola, HIV, and global connectivity.

Authors contribution Both authors contributed to the idea for the article, Piret Vilborn performed the literature search and drafted the work, which was approved by both authors. Both authors commented on previous versions of the manuscript, read and approved the final manuscript. 


\section{Declarations}

Ethical approval Not applicable.

Conflict of interest The authors declare no conflict of interest.

\section{References}

1. Bradbury-Jones C, Isham L (2020) The pandemic paradox: the consequences of COVID-19 on domestic violence. J Clin Nur 29:2047-2049

2. Guterres, A (2020) UN chief calls for domestic violence 'ceasefire'amid 'horrifying global surge.'. Retrieved from UN News. https://news.un.org/en/story/2020/04/1061052. Accessed 05 Jan 2021

3. Viero A et al (2021) Violence against women in the Covid-19 pandemic: a review of the literature and a call for shared strategies to tackle health and social emergencies. Forensic Sci Int 319:110650

4. Andrew MC (2020) An increasing risk of family violence during the Covid-19 pandemic: strengthening community collaborations to save lives. Forensic Sci Int: Reports 2:100089. https://doi.org/ 10.1016/j.fsir.2020.100089

5. Freeman AJ, Senn DR, Arendt DM (2005) Seven hundred seventy eight bite marks: analysis by anatomic location, victim and biter demographics, type of crime, and legal disposition. J Forensic Sci 50(6):1436-1443

6. George R, George A (2020) COVID-19 as an occupational disease? S Afr Med J 110(4):260-260

7. Emilio N, Hemlata P, Francesco L (2020) Dental autopsy recommendations in SARS-CoV-2 infected cases. Forensic Sci Int: Synergy 2:154-156. https://doi.org/10.1016/j.fsisyn.2020.04.004

8. Reinprecht $\mathrm{S}$ et al (2017) An analysis of dental intercanine distance for use in court cases involving bite marks. Int J Legal Med 131(2):459-464

9. Bernitz H et al (2008) An integrated technique for the analysis of skin bite marks. J Forensic Sci 53(1):194-198

10. Naether $\mathrm{S}$ et al (2012) The examination and identification of bite marks in foods using 3D scanning and 3D comparison methods. Int J Legal Med 126(1):89-95

11. Stols G, Bernitz H (2010) Reconstruction of deformed bite marks using affine transformations. J Forensic Sci 55(3):784-787

12. Molina A, Martin-de-las-Heras S (2015) Accuracy of 3D scanners in tooth mark analysis. J Forensic Sci 60(Suppl 1):S222-S226

13 Moher D et al (2009) Preferred reporting items for systematic reviews and meta-analyses: the PRISMA statement. BMJ 339:b2535

14. Martin-de-Las-Heras S, Tafur D, Bravo M (2014) A quantitative method for comparing human dentition with tooth marks using three-dimensional technology and geometric morphometric analysis. Acta Odontol Scand 72(5):331-336

15. Przystanska A et al (2015) Skuteczność metod 2D i 3D w analizie eksperymentalnych śladów ugryzień. Dent Med Probl 52(1):86-92

16. de Sainte Croix MM et al (2016) Three-dimensional imaging of human cutaneous forearm bite marks in human volunteers over a 4 day period. J Forensic Leg Med 40:34-39

17. Chong GTF, Forgie AH (2017) A pilot study to analyze the uniqueness of anterior teeth using a novel three-dimensional approach. JFI 67(3):361-378

18. Franco A et al (2017) Uniqueness of the anterior dentition threedimensionally assessed for forensic bitemark analysis. J Forensic Leg Med 46:58-65
19. Franco A et al (2017) Three-dimensional analysis of the uniqueness of the anterior dentition in orthodontically treated patients and twins. Forensic Sci Int 273:80-87

20. Rajshekar M et al (2017) The reliability and validity of measurements of human dental casts made by an intra-oral 3D scanner, with conventional hand-held digital callipers as the comparison measure. Forensic Sci Int 278:198-204

21. Ali IK, Sansare K, Karjodkar FR (2018) Analysis of intercanine distance and dimensional changes in bite marks on foodstuffs using cone beam computed tomography. Am J Forensic Med Pathol 39(3):213-217. https://doi.org/10.1097/paf.00000 00000000399

22. Corte-Real A et al (2018) Tri-dimensional pattern analysis of foodstuff bitemarks-a pilot study of tomographic database. Forensic Sci Int 288:304-309

23. Fournier $\mathrm{G}$ et al (2019) Three-dimensional analysis of bitemarks using an intraoral scanner. Forensic Sci Int 301:1-5

24. Ramos B et al (2019) A new method to geometrically represent bite marks in human skin for comparison with the suspected dentition. Aust J Forensic Sci 51(2):220-230

25 Fournier G et al (2020) Three-dimensional analysis of bitemarks: a validation study using an intraoral scanner. Forensic Sci Int 309:110198

26. Molina A, et al (2020) Dental parameter quantification with semi-automatized computational technology for the analysis of human bitemarks. Aust J Forensic Sci 1-11. https://doi.org/10. 1080/00450618.2020.1793385

27 Donovan TE, Chee WW (2004) A review of contemporary impression materials and techniques. Dent Clin North Am 48(2):vi-vii (445-70)

28. Means CR, Flenniken IE (1970) Gagging - a problem in prosthetic dentistry. J Prosthet Dent 23(6):614-620

29. Wismeijer D et al (2014) Patients' preferences when comparing analogue implant impressions using a polyether impression material versus digital impressions (Intraoral Scan) of dental implants. Clin Oral Implants Res 25(10):1113-1118

30. Patzelt, S.B., et al., The time efficiency of intraoral scanners: an in vitro comparative study. Journal of the American Dental Association (1939), 2014. 145(6): p. 542-51.

31. Errickson D et al (2020) The effect of different imaging techniques for the visualisation of evidence in court on jury comprehension. Int J Legal Med 134(4):1451-1455

32. Fahrni S et al (2019) An exploratory study toward the contribution of 3D surface scanning for association of an injury with its causing instrument. Int J Legal Med 133(4):1167-1176

33. Aragon ML et al (2016) Validity and reliability of intraoral scanners compared to conventional gypsum models measurements: a systematic review. Eur J Orthod 38(4):429-434

34. Kim YJ, Cha ES, Lee WJ (2016) Occupational radiation procedures and doses in South Korean dentists. Community Dent Oral Epidemiol 44(5):476-484

35. Marques $\mathbf{J}$ et al (2013) Analysis of bite marks in foodstuffs by computer tomography (cone beam CT)-3D reconstruction. J Forensic Odontostomatol 31(1):1-7

36. Thali MJ et al (2003) Bite mark documentation and analysis: the forensic 3D/CAD supported photogrammetry approach. Forensic Sci Int 135(2):115-121

37. Slot L, Larsen PK, Lynnerup N (2014) Photogrammetric documentation of regions of interest at autopsy-a pilot study. J Forensic Sci 59(1):226-230

38. Buck U et al (2018) Validation and evaluation of measuring methods for the 3D documentation of external injuries in the field of forensic medicine. Int J Legal Med 132(2):551-561

39. Flies MJ et al (2019) Forensic 3D documentation of skin injuries using photogrammetry: photographs vs video and manual vs automatic measurements. Int J Legal Med 133(3):963-971 
40. Urbanova P, Hejna P, Jurda M (2015) Testing photogrammetrybased techniques for three-dimensional surface documentation in forensic pathology. Forensic Sci Int 250:77-86

41. Villa C (2017) Forensic 3D documentation of skin injuries. Int J Legal Med 131(3):751-759

42. Franco A et al (2015) The uniqueness of the human dentition as forensic evidence: a systematic review on the technological methodology. Int J Legal Med 129(6):1277-1283

43. Bernitz H et al (2000) Comparison of bitemarks left in foodstuffs with models of the suspects' dentitions as a means of identifying a perpetrator. J Forensic Odontostomatol 18(2):27-31
44. Blackwell SA et al (2007) 3-D imaging and quantitative comparison of human dentitions and simulated bite marks. Int J Legal Med 121(1):9-17

45. Sheets HD, Bush PJ, Bush MA (2013) Patterns of variation and match rates of the anterior biting dentition: characteristics of a database of 3D-scanned dentitions. J Forensic Sci 58(1):60-68

Publisher's note Springer Nature remains neutral with regard to jurisdictional claims in published maps and institutional affiliations. 